\title{
Yoga and physiology: An update.
}

\section{Jabir P K*, Kumar Sai Sailesh}

Department of Physiology, DM Wayanad Institute of Medical Sciences, Naseera Nagar, Meppadi, Waynad, Kerala, India.

Accepted on 26 October, 2017

\section{Introduction}

Nearly 5000 years ago Great Indian sage Patanjali has explained yoga as a tradition and system that controls body and mind in his treatise yoga sutra [1]. 'Yoga' is derived from the Sanskrit root 'Yuj' which includes meanings of binding to and joining to Yoga integrates body, breath and mind. It includes postures (asanas), controlled breathing (pranayama), concentrating the thoughts (meditation) and recitation of phrases called mantras. It makes subject to experience good health and happiness and improves quality of life. Studies showed that regular yoga practice reduced stress levels and also reduces stress in the morning hours of exam. Yoga improves cardiac parameters and pulmonary function test. Yoga is a practical discipline incorporating a wide variety of practices whose goal is the development of a state of mental and physical health, well-being, inner harmony and ultimately "a union of the human individual with the universal and transcendent Existence". These practices are believed to have originated in early civilization on the Indian subcontinent and have been practiced historically in India and throughout East Asia. It includes the practice of meditation, regulation of respiration with a variety of breathing exercises, and the practice of a number of physical exercises and postures, in which the focus is more on isometric exercise and stretching than on aerobic fitness. Asanas and pranayama are two limbs of ashtanga yoga of patanjali which help individual to integrate mind and body. Healthy body and mind is a prerequisite for a sadhaka to progress further towards enlightment. Extensive use of asana, pranayama and meditation in line with hatayoga is observed in modern society. Yoga helps to lower blood pressure, increase lung capacity, improves respiratory function and heart rate, boost circulation and muscle tone. All the systems of the body are stimulated and balanced by practicing yoga. In effect there is increased mental clarity, and greater sense of wellbeing. Emotions can be controlled by regular practice of yoga. Practicing for few months results in good health by triggering neurohormonal mechanism [2]. A few month practice of yoga triggers neurohormonal mechanism that bring about health benefits. Autonomic nervous system is stabilized. Subjects can attain a sympatho parasympathetic balance with a tendency toward parasympathetic nervous system dominance [3]. Heart rate, blood pressure, reactivity to stressful stimuli is decreased. In EEG, alpha waves, theta, delta waves increased showing relaxed state of mind. This results in sensory attenuation that is minimal sensory input, motor attenuation that is minimal motor input and leads to improvement of higher intellectual activities. On Cardiovascular system practicing yoga decreases heart rate and systemic BP. By increasing baroreflex sensitivity it increases cardiovascular efficiency. On respiratory system by parasympathetic nervous system dominance and decreased sympathetic activity it decreases respiratory rate, increases tidal volume, vital capacity, breath holding time, maximum breathing capacity and respiratory efficiency increases and respiration become smoother. On neurohormonal activity regular yogic practices lead to reduction in intrinsic hormonal activity such as decrease in urinary excretion of catecholamine [4], thyroxin and oxytocin level increases, decreases fasting blood glucose. On skeletal-muscular system, EMG activity decreases, musculo-skeletal flexibility and joint range of movement increases, endurance, strength, energy level increases. On digestive system it increases blood flow to GIT, stimulates peristalsis, relaxes digestive system and leads to more effective elimination. Psychological benefits include improvement in mood and social adjustment [5].

Hence, practicing yoga must be incorporated in routine day life style for improving the quality and quantity of life.

\section{References}

1. Jain AK. Textbook of medical physiology. 4th ed. New Delhi: Avichal publishing company. 2011;498-512.

2. Rama S. Lectures on Yoga: Practical Lessons on Yoga (Glenview, IL: Himalayan International Institute of Yoga, Science and Philosophy, rev.), vi, cited in Ankerberg and Weldon. Encycl New Age Beliefs. 1976;596.

3. Muralikrishnan K, Balakrishnan B, Balasubramanian K, et al. Measurement of the effect of Isha Yoga on cardiac autonomic nervous system using short-term heart rate variability. J Ayurveda Integr Med. 2012;3(2):91-6.

4. Wenger MA, Bagchi BK. Studies of autonomic functions in practitioners of yoga in India. Behav Sci. 1961;6(4): 312-23.

5. Sengupta P. Challenge of infertility: How protective the yoga therapy is? Anc Sci Life. 2012;32(1):61-2.

\section{*Correspondence to}

Dr. Jabir P K,

Assistant Professor, Department of Physiology,

DM Wayanad Institute of Medical Sciences,

Naseera Nagar, Meppadi,

Waynad, Kerala, India

E-mail: jabspk@gmail.com 